\title{
Ahşap ve Mobilya İmalatı Yapan Bir İşyerinde Risklerin Belirlenmesi ve Örnek Risk Analiz Çalıșması
}

\author{
Determination of Risks and Sample Risk Analysis Study in a Wood and Furniture Manufacturing \\ Workplace
}

Elif ÇELENK KAYA ${ }^{1}$, Necla İrem ÖLMEZOĞLU İR İ², Kubilay PEDİs ${ }^{3}$

\begin{abstract}
ÖZ
Ülkemizdeki iş kollarında önemli bir yere sahip olan mobilya imalat sektöründe kullanılan makineler sanayi devrimi ile oldukça gelişmiştir. Çok çeşitli ürün yelpazesine sahip olan mobilya sektörü iş güvenliği açısından tehlikeli sınıfta yer almaktadır. Alanda kullanılan makine ve ekipmanlar, çalışanların maruz kaldığı gürültü, toz ve kimyasallar iş sağlı̆̆ ve güvenliğinin bu sektörde ne kadar önemli olduğunun bir göstergesidir. Mobilya sektörü, iş kazalarının en çok yaşandığı işyerlerinin sıralamasında maden, inşaat, nakliyat, metal sektörlerinden sonra 5.sirada gelmektedir. Bu açıdan çalışmada ahşap ve mobilya imalatı yapan bir işyerinde mevcut riskler belirlenmiş ve $\mathrm{L}$ tipi Matris kullanılarak risk analiz çalışması gerçekleştirilmiştir. Yapılan risk analiz çalışmasında 26’s1 "Yüksek Risk", 20'si “Orta Risk", 3“üu "Düşük Risk" olarak toplam 49 risk tespit edilmiștir. Son olarak tespit edilen risklerin ortadan kaldırılması veya en aza indirilmesi için önerilerde bulunulmuştur.
\end{abstract}

Anahtar Kelimeler: İş Kazası, İş Sağlığı ve Güvenliği, Mobilya İmalatı, Risk

\begin{abstract}
The machines used in the furniture manufacturing sector, which has an important place in the business lines of our country, have developed considerably with the industrial revolution. The furniture sector, which has a wide range of products, is in the dangerous class in terms of occupational safety. Machinery and equipment used in the field, noise, dust and chemicals to which employees are exposed are an indicator of how important occupational health and safety is in this sector. The furniture sector ranks 5 th after the mining, construction, transportation and metal sectors in the ranking of the workplaces where work accidents occur most. In this regard, the present risks were determined in a workplace producing wood and furniture, and a risk analysis study was carried out using the L-type Matrix. In the risk analysis study, a total of 49 risks were determined, 26 of which were "High Risk", 20 of which were "Medium Risk" and 3 of them were "Low Risk". Finally, suggestions have been made to eliminate or minimize the risks identified.
\end{abstract}

Keywords: Occupational Accident, Occupational Health and Safety, Furniture Manufacturing, Risk

*Bu çalışma Gümüşhane Üniversitesi Fen Bilimleri Enstitüsünde 16.03.2018 tarihinde Yüksek Lisans tezi olarak sunulmuştur.

${ }^{1}$ Prof.Dr. Gümüşhane Üniversitesi Sağlık Bilimleri Fakültesi, İş Sağlığı ve Güvenliği Bölümü, elifcelenk1629@ @otmail.com,ORCID:0000-00027811-7669

${ }^{2}$ Arş.Gör. Gümüşhane Üniversitesi Sağlık Bilimleri Fakültesi, İş Sağlığı ve Güvenliği Bölümü, neclairem@hotmail.com, ORCID:0000-00032997-3343

${ }^{3}$ Tezli Y.L.Öğr.Gümüşhane Üniversitesi, Fen Bilimleri Enstitüsü, Ormancılık ve Çevre Bilimleri Anabilim Dalı,kubilaypediss@gmail.com,

İletişim / Corresponding Author: Elif ÇELENK KAYA Geliş Tarihi / Received: 26.02.2019


İş sağlığı ve güvenliği konusu çalışma hayatı ve çalışma hukuku açısından oldukça önemlidir. ${ }^{1}$ İş sağlığı ve güvenliği konusu içerisinde ise iş kazaları ve önleme konularının ayrı bir önemi bulunmaktadır. Bakıldığında ülkemiz ölümlü iş kazalarında Avrupa'da birinci sirada yer almaktadır. ${ }^{2}$ Sosyal Güvenlik Kurumu'nun son verilerine (2017) göre, 2015 yılında 241.547 iş kazası 2016 yılında ise 286.068 iş kazası sayısı yaşanmıştır. Buna göre iş kazası sayısı bir önceki yıla göre yaklaşık \%18 artmıştır. En fazla iş kazası 2016 yılında gerçekleşmiş ve bu yılda 1405 kişi iş kazasında hayatını kaybetmiştir. Bu sayı bir önceki seneye göre yaklaşık olarak \%12 artmıştır. ${ }^{3}$ Görüldüğü gibi rakamlar ülkemizde iş sağlığı ve güvenliği alanında yaşanan sorunların kabul edilemez olduğunu göstermektedir. ${ }^{2}$

Son derece ciddi neticeleri olan çalışan kişinin yanı sıra ailelerini, işvereni ve dolayısıyla ülke ekonomisini olumsuz etkileyen iş kazalarının ve meslek hastalıklarının önüne geçilmesi gerekmektedir. Bunun için işletmedeki riskleri tümüyle yok etmek veya en aza indirmek için yapılacak risk analiz çalışmaları büyük önem arz etmektedir. ${ }^{4} \mathrm{Bu}$ çalışmada, ahşap ve mobilya üretimi yapan bir işyerinde çalışma ortamı ve şartlarından kaynaklı tehlikeler ile imalatta kullanılan hammaddeler, makine ve ekipman, çalışan ve sistem hatalarından meydana gelen tehlikeler sonucu ortaya çıkabilecek riskler, risk analiz çalışmasıyla değerlendirmeye alınarak olası iş kazası ve meslek hastalıklarını önlemeyi amaçlamaktadır.

\section{İş Sağlığı ve Güvenliği Tanımı}

Geleneksel anlamıyla iş sağlığı ve güvenliği; "işyerlerini işin yürütümü nedeniyle oluşan tehlikelerden uzaklaştırmak ve sağliğa zarar verebilecek koşullardan arındırarak, daha iyi bir çalışma ortamı sağlamak için yapılan sistemli çalışmalar" olarak tanımlanmaktadır. Modern anlamda iş sağlığı ve güvenliği ise; işin yürütülmesi sırasında doğan sağlığa zarar verecek koşullardan ve güvenliği tehlikeye düşürecek

\section{GİRIŞ}

durum ve davranışlardan korunmak, üretimin devamlılığını sağlamak ve verimliliği arttırmak amacıyla yürütülen sistemli ve bilimsel çalışmalar olarak tanımlanmaktadır. ${ }^{5}$

\section{İş Sağlığı ve Güvenliğinin Amacı}

İş sağlığ1 ve güvenliği (İSG) uygulamaları, tüm mesleklerde çalışma koşullarının sebep olduğu olumsuz etkilerin önlenmesi; fiziksel, zihinsel, sosyal açıdan çalışanların verimliliklerinin yükseltilmesi ve korunmasını amaçlamaktadır. ${ }^{6}$

\section{Risk Değerlendirmesine ilişkin Tanımlar}

Risk değerlendirmesinin tam olarak açıklanabilmesi için bazı temel kavramların tanımlamalarına ihtiyaç duyulmaktadır. $\mathrm{Bu}$ kavramlardan en önemlileri "risk" ve "tehlike" tanımıdır. Birçok kavramda olduğu gibi riski tanımlamakta ve ölçümlemekte de nitel ve nicel yöntemlerden yararlanılmaktadır.

Molak, nicel yönüyle riski, endüstriyel bir süreç içinde oluşan olumsuz sonuçların meydana gelme ihtimali olarak tanımlamış ve bu olasılıklara karşı geliştirilmesi gereken yöntemlerin gerekliliğinden bahsetmiştir. ${ }^{7}$

Modarres riski, tehlikeli bir olay sonucu yaralanma ve ölüm ihtimali olarak tanımlamış ve tehlikeli durum için güvenlik tedbirleri yetersiz ise ölüm ve yaralanma vakalarının yaşanma olasılığı devam edeceğini; bu durumu da risk olarak adlandırdığını belirtmiştir. ${ }^{8}$

İş sağlığ 1 ve güvenliği risk değerlendirme yönetmeliğinde (ISGGRD) ise risk, "tehlikeden kaynaklanacak kayıp, yaralanma ya da başka zararlı sonuç meydana gelme ihtimali” şeklinde tanımlanmıştır.

Risk değerlendirmesi için başka bir önemli kavram ise tehlike'dir. ISGRD yönetmeliğine göre tehlike, işyerinde var olan ya da dışarıdan gelebilecek, çalışanı veya işyerini etkileyebilecek zarar veya hasar verme potansiyeli olarak tanımlanmaktadır. ${ }^{9}$

Tehlike ve risk kavramlarına göre risk değerlendirmesi ise; işyerinde var olan ya da 
dişarıdan gelebilecek tehlikelerin

belirlenmesi, bu tehlikelerin riske dönüşmesine yol açan faktörler ile tehlikelerden kaynaklanan risklerin analiz edilerek derecelendirilmesi ve kontrol tedbirlerinin kararlaştırılması amacıyla yapılması gerekli çalışmalar şeklinde tanımlanmaktadır. ${ }^{10}$ Diğer bir deyişle risk değerlendirmesi, işyerlerinde var olan ya da var olması mümkün olan risklerin belirlenmesi ve belirlenen risklerin önem derecelerinin tespit edilerek etkili bir önleme planının hazırlanmasını amaçlayan çalışmalar bütünüdür.

\section{Mobilya Sektörünün İş Sağlığı ve Güvenliği Açısından Değerlendirilmesi}

Mobilya; Latince "mobilius" sözcüğünden türetilmiş bir kavram olup insanların günlük yaşamdaki yemek yeme, dinlenme, oturma, çalışma gibi temel ihtiyaçlarını güvenli ve konforlu bir şekilde karşılamak üzere estetik görünümlü, işlevsel ve genellikle ağaç malzemeden imal edilmiş kullanım eşyaları şeklinde tanımlanmıştır. ${ }^{11}$

Yukarıda bahsedilen gündelik ihtiyaçları karşılamaya yönelik olarak üretilen mobilyalar fonksiyonel eşyalardır. ${ }^{11} \mathrm{Bu}$ açıdan değerlendirildiğinde artan ihtiyacı karşılamak amacıyla sektördeki üretim miktarının her geçen gün $\operatorname{arttığ1}$ görülmektedir.

\section{Türkiye'de Mobilya Sektörü}

Türkiye'de emeğin yoğun olarak kullanıldığı mobilya sektörü, birçok sektör ile olan bağlantısı ve gelişen teknolojik imkanlarla birlikte imalat sanayi içerisinde önemli bir konumdadır. ${ }^{12}$ Türkiye ${ }^{\text {ee }} \mathrm{de}$ istihdam açısından büyük bir paya sahip olan mobilya sektörü, kentleşme oranının artması ve oluşan iç talebe paralel olarak son yıllarda hızlı bir büyüme kaydetmiştir. Türkiye'de mobilya sektöründeki üretimin 6 milyar dolar olduğu tahmin edilmekte olup Türkiye'nin Gayri Safi Milli Hasılası içinde \% 0,75 seviyesine yakın bir paya sahiptir. ${ }^{13}$

Mobilya sektörünün ülkemizde büyümesine paralel olarak iş kazası sayısı da son altı yılda genel olarak artış göstermekteyken, sektörde 2012 y1lından itibaren 6331 sayılı İş Sağlığı ve Güvenliği Kanununun getirdiği yükümlülükler ile beraber iş kazalarının bildiriminde önemli bir artış olduğu görülmektedir. $\mathrm{Bu}$ durumun sonucu olarak bildirimi yapılan iş kazası sayılarında 2011-2016 yılları arasında dikkate değer bir fark oluşmuştur (Şekil 1).

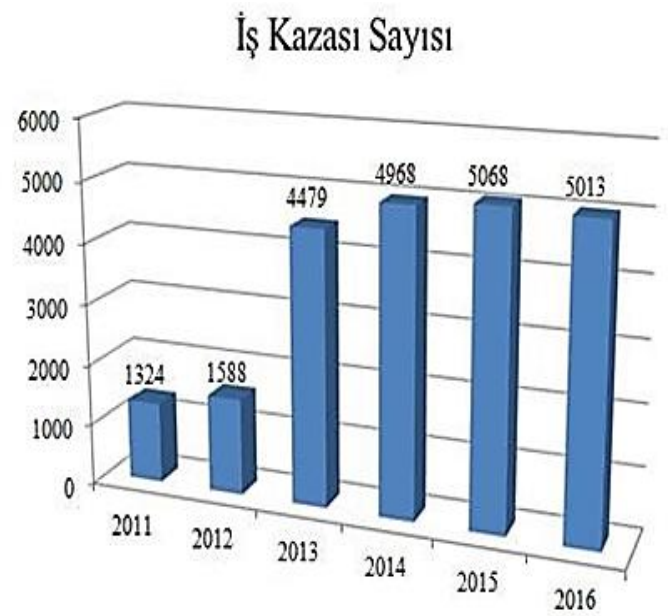

Şekil 1. Mobilya Sektöründe İş Kazası Sayılarının Yıllara Göre Dağılımı ${ }^{14}$

Ancak meslek hastalığı tanı ve teşhisindeki yetersizlikler, mobilya sektörü ile ilgili meslek hastalıklarının yavaş ilerlemesi gibi sebeplerden dolayı sektörde tespit edilen meslek hastalığı sayısı tahmin edilenin altında seyretmektedir (Şekil 2). ${ }^{15}$

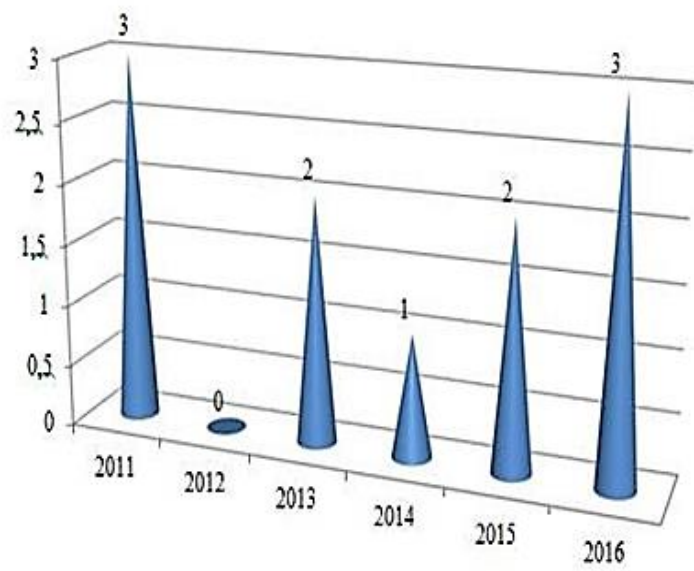

Şekil 2. Mobilya Sektöründe Meslek Hastalığı İstatistikleri ${ }^{14}$

Mobilya sektöründe Şekil 1 ve Şekil 2 birlikte değerlendirildiğinde iş kazası ve meslek hastalığı sayılarının halen yüksek olduğu görülmektedir. Ancak işyerlerinde detaylı ve gerçekçi risk değerlendirme çalışmalarının yapılması bu oranların 
azalmasını sağlayacaktır. $\mathrm{Bu}$ açıdan çalışmanın alana önemli bir katkı sunacağı düşünülmektedir.

\section{MATERYAL VE METOT}

6331 sayılı İş Sağlığı ve Güvenliği Kanunu ve Risk Değerlendirmesi Yönetmeliği ile işyerlerinde risk değerlendirmesi yapılması yasal olarak gerekli kılınmıştır. Ancak ilgili yönetmelikte risk değerlendirilmesi yapılırken kullanılacak yöntem veya yöntemlerle ilgili bir bilgiye yer verilmeyip kalitatif, kantitatif ya da karma yöntemlerden birinin seçilebileceği belirtilmiştir.

$\mathrm{Bu}$ çalışmada yöntem olarak, basit uygulanabilirliğinden dolayı L Tipi Risk Değerlendirme Karar Matrisi yöntemi (5 x 5 Matris diyagramı) kullanılmıştır. Risk matrisleri, tehlike kaynaklarını veya risk düzeyi doğrultusunda risk büyüklügünü derecelendirmek için kullanılır. Birden fazla risk olduğunda, bu riskler arasında eleme aracı olarak da sonuç/analiz matrisinden yararlanılabilir. Uygun şekilde uygulanan bu teknik ile hangi riskin daha fazla veya daha ayrıntılı analize ihtiyaç duyduğu, hangi risklere öncelikli olarak müdahale edilmesi gerektiği veya hangisinin daha üst düzey bir yönetimle analizinin yapılması gerektiği saptanabilir. Matris kullanımı ile aynı zamanda hangi riskin artık önem arz etmediği ve kaynak ayrılmaması gerektiği de saptanabilir ${ }^{16}$

Matris yönteminde Risk;

Risk $=$ Tehdidin Gerçekleşme İhtimali (Olasılık) X Tehdidin Etkisi (Etki)

formülü kullanılarak belirlenmiştir.

Çalışmada öncelikle Mobilya Atölyesi için mevcut tehlikeler belirlenmiş ve bu tehlikelerin gerçekleşme olasılığı L Tipi Risk Değerlendirme Karar Matrisi yöntemine (5 x 5
Matris diyagramı) göre Tablo 1 kullanılarak çok küçük, küçük, orta, yüksek ve çok yüksek olarak sırasıyla 1'den 5'e kadar puanlanmıştır.

Tablo 1. Olasılık Skorları

\begin{tabular}{lrl}
\hline \multicolumn{2}{c}{ SONUÇ } & \multicolumn{1}{c}{ OLASILIK } \\
\hline $\begin{array}{l}\text { Çok } \\
\text { Küçük }\end{array}$ & 1 & Hemen hemen hiç \\
\hline Küçük & 2 & $\begin{array}{l}\text { Çok az (yılda bir kez), sadece } \\
\text { anormal durumlarda }\end{array}$ \\
\hline Orta & 3 & Az (yılda bir kez) \\
\hline Yüksek & 4 & Siklıkla (ayda bir) \\
\hline $\begin{array}{l}\text { Çok } \\
\text { Yüksek }\end{array}$ & 5 & $\begin{array}{l}\text { Çok sıklıkla (haftada bir, her gün), } \\
\text { normal çalışma şartlarında }\end{array}$ \\
\hline
\end{tabular}

Ardından Tablo 2 kullanılarak tehlikelerin oluştuğunda verebilecekleri zarar; çok hafif, hafif, orta, ciddi ve çok ciddi olarak sırasıyla yine 1'den 5'e kadar puanlanmıştır.

\section{Tablo 2. Şiddet Skorları}

\begin{tabular}{lrl}
\hline \multicolumn{1}{c}{ SONUÇ } & \multicolumn{1}{c}{ OLASILIK } \\
\hline $\begin{array}{l}\text { Çok } \\
\text { Hafif }\end{array}$ & 1 & $\begin{array}{l}\text { İş saati kaybı yok, ilkyardım } \\
\text { gerektiren }\end{array}$ \\
\hline Hafif & 2 & $\begin{array}{l}\text { İş günü kaybı yok, kalıcı etkisi } \\
\text { olmayan ayakta tedavi, ilkyardım } \\
\text { gerektiren }\end{array}$ \\
\hline Orta & 3 & $\begin{array}{l}\text { Hafif yaralanma, yatarak tedavi } \\
\text { gerektiren }\end{array}$ \\
\hline Ciddi & 4 & $\begin{array}{l}\text { Ciddi yaralanma, uzun süreli tedavi, } \\
\text { meslek hastalığı }\end{array}$ \\
\hline Çok & 5 & Ölüm, sürekli iş göremezlik \\
Ciddi & & \\
\hline
\end{tabular}

Yukarıda verilen formüle göre belirlenen olasılık ve şiddet değerlerinin çarpılmasıyla her bir risk için risk skoru puanı (RS) belirlenmiş ve Tablo 3 ile gösterilen Risk Skor Matrisi (RSM) tablosuna yerleştirilmiştir.

Tablo 3. Olasılık X Şiddet Skorları

\begin{tabular}{|c|c|c|c|c|c|c|c|}
\hline \multirow{3}{*}{\multicolumn{2}{|c|}{ R=Olasılık X Şiddet }} & & \multicolumn{5}{|c|}{ Şiddet } \\
\hline & & & Çok Ciddi & Ciddi & Orta & Hafif & Çok Hafif \\
\hline & & & 5 & 4 & 3 & 2 & 1 \\
\hline \multirow{5}{*}{$\frac{y}{\overline{\bar{n}}}$} & Çok Yüksek & 5 & 25 & 20 & 15 & 10 & 5 \\
\hline & Yüksek & 4 & 20 & 16 & 12 & 8 & 4 \\
\hline & Orta & 3 & 15 & 12 & 9 & 6 & 3 \\
\hline & Küçük & 2 & 10 & 8 & 6 & 4 & 2 \\
\hline & Çok Küçük & 1 & 5 & 4 & 3 & 2 & 1 \\
\hline
\end{tabular}


Son olarak Tablo 4 kullanılarak risk skorlarının değerlerine göre sonucun kabul edilebilirlik değerleri belirlenmiş ve riskin büyüklügüne göre işin durdurulmasına veya alınması gereken önlemlerin önceliğine karar verilmiştir.

\section{Araştırmanın Etik Yönü}

Araştırmanın yapılabilmesi için Erzincan ilinde bulunan Arslan Mobilya adlı işyerinden 15.09.2018 tarihinde gerekli izinler alınmıştır.

Tablo 4. Skor Sonuçlarına Göre Yapılacak Çalışmalar

\begin{tabular}{|c|c|}
\hline Sonuç & Yapılacak Çalışmalar \\
\hline $15,16,20,25$ & Kabul Edilemez Risk: \\
\hline Yüksek & $\begin{array}{l}\text { Risk kabul edilebilir seviyeye çekilmeden çalışmaya başlanamaz ve çalışma yapılıyor ise } \\
\text { durdurulur. Bu risklerle ilgili hemen çalışma yapılmalıdır. }\end{array}$ \\
\hline$\underline{8,9,10,12}$ & Dikkate Değer Risk: \\
\hline Orta & $\begin{array}{l}\text { Bu risklerle mümkün olduğu kadar çabuk müdahale edilmeli ve ilave tedbirler alınarak kontrollü } \\
\text { çalışılmalıdır. }\end{array}$ \\
\hline$\frac{1,2,3,4,5,6,}{\text { Düșük }}$ & $\begin{array}{l}\text { Kabul Edilebilir Risk: } \\
\text { Acil tedbir gerektirmeyebilir, ancak tedbirler düșünülmeli ve iyileștirmeye devam edilmelidir. }\end{array}$ \\
\hline
\end{tabular}

\section{BULGULAR VE TARTIŞMA}

Ahşap ve mobilya sektöründe faaliyet gösteren bir firmada yapılan bu çalışmada L tipi Matris yöntemi kullanılarak risk analiz çalışması gerçekleştirilmiştir. Bu analize ilişkin sonuçlar aşağıda yer almaktadır (Tablo 5).

\section{Tablo 5. Risk Analiz Tablosu}

\begin{tabular}{|c|c|c|c|c|c|c|c|c|c|c|c|c|}
\hline 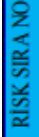 & RESIM & $\begin{array}{c}\text { FALIYET } \\
\text { ALANI }\end{array}$ & TEHLIKESI & $\begin{array}{l}\text { MEVCUT } \\
\text { DURUM }\end{array}$ & $\frac{\vec{x}}{x}$ & 兰 & 莶 & $\begin{array}{c}\text { RISK } \\
\text { PUANI }\end{array}$ & $\begin{array}{c}\text { ÖNEM } \\
\text { DERECESI }\end{array}$ & $\begin{array}{c}\text { GEREKU DOZELTICI } \\
\text { VE ONLEYICI } \\
\text { FALYYET }\end{array}$ & SORUMLU & TERMIN \\
\hline 1 & & ORETIM & $\begin{array}{l}\text { KABLOLARIN } \\
\text { DAĞINIK BIR } \\
\text { SEKILDE } \\
\text { BULUNMASI }\end{array}$ & $\begin{array}{c}\text { AHŞAP } \\
\text { MALZEMELERIN } \\
\text { IȘLENDIĞI YERDE } \\
\text { KABLO } \\
\text { KANALLARI } \\
\text { BULUNMAMAK- } \\
\text { TADIR }\end{array}$ & $\begin{array}{l}\text { TAKILMA, } \\
\text { DŐSME }\end{array}$ & 3 & 5 & 15 & 1. DERECE & \begin{tabular}{|c|} 
ELEKTRIK \\
BAĞLANTI \\
KABLOLARI VE \\
AÇIK UÇLAR \\
YALITKAN KAPAK \\
ILE \\
KAPATILMALIDIR \\
\end{tabular} & $\begin{array}{c}\text { IŞVEREN } \\
\text { VE } \\
\text { ÇALISSAN }\end{array} \mid$ & $\begin{array}{l}\text { EN KISA } \\
\text { SOREDE }\end{array}$ \\
\hline 2 & & ORETIM & \begin{tabular}{|c|} 
UZATMA \\
KABLOLARININ \\
SIK KULLANIMI, \\
T FIŞLER \\
ARACILIĞI ILE \\
FAZLAA \\
CIHAZLARININ \\
BAĞLANMASI
\end{tabular} & $\begin{array}{c}\text { IŞYERINDEKI } \\
\text { ÇOĞU } \\
\text { MAKINALARININ } \\
\text { UZATMA } \\
\text { KABLOLARI ILE T } \\
\text { FISSLER ARACILIĞI } \\
\text { ILE KULLANIL- } \\
\text { MAKTADIR }\end{array}$ & $\begin{array}{l}\text { YANGIN, } \\
\text { ELEKTRIK } \\
\text { ÇARPMASI }\end{array}$ & 3 & 5 & 15 & 1. DERECE & \begin{tabular}{|c|} 
KISA OLAN \\
KABLOLAR \\
KULLANILMALI \\
YADA CIHAZLARIN \\
FIȘLERI DOG̈RUDAN \\
PRIZE \\
TAKILMALIDIR
\end{tabular} & IȘVEREN & SOREKLI \\
\hline 3 & & ORETIM & \begin{tabular}{|c|} 
ELEKTRIK \\
BAĞLANTI \\
KABLOLARI VE \\
PRIZLERIN \\
KAPAKLI \\
OLMAMASI \\
\end{tabular} & $\begin{array}{l}\text { ISYYERINDE } \\
\text { BULUNAN } \\
\text { PRIZLERIN } \\
\text { KAPAKLI } \\
\text { OLMAMASI }\end{array}$ & $\begin{array}{l}\text { YANGIN, } \\
\text { ELEKTRIK } \\
\text { ÇARPMASI }\end{array}$ & 3 & 5 & 15 & 1.DERECE & $\begin{array}{c}\text { BÜTONN PRIZLER } \\
\text { TALAS } \\
\text { DOLMAMASI IÇIN } \\
\text { KAPAKLI PRIZLER } \\
\text { KULLANILMASI }\end{array}$ & IȘVEREN & SOREKLI \\
\hline 4 & & ORETIM & $\begin{array}{l}\text { AYDINLATMA- } \\
\text { LARIN YETERSIZ } \\
\text { OLMASI }\end{array}$ & $\begin{array}{c}\text { ISSYERININ } \\
\text { GENELINDE GÜN } \\
\text { IȘIĞI KULLAANIL- } \\
\text { MAKTADIR }\end{array}$ & YARALANMA & 3 & 4 & 12 & 2. DERECE & \begin{tabular}{|c|} 
AYDINLATMALI \\
ClHAZLARI \\
YETERLI OLÇOODE \\
OLMALI VE BUNUN \\
IÇIN AYDINLATMA \\
OLÇUMMÜ YAPMALI
\end{tabular} & IŞVEREN & SOOREKLI \\
\hline
\end{tabular}


Tablo 5 (Devam). Risk Analiz Tablosu

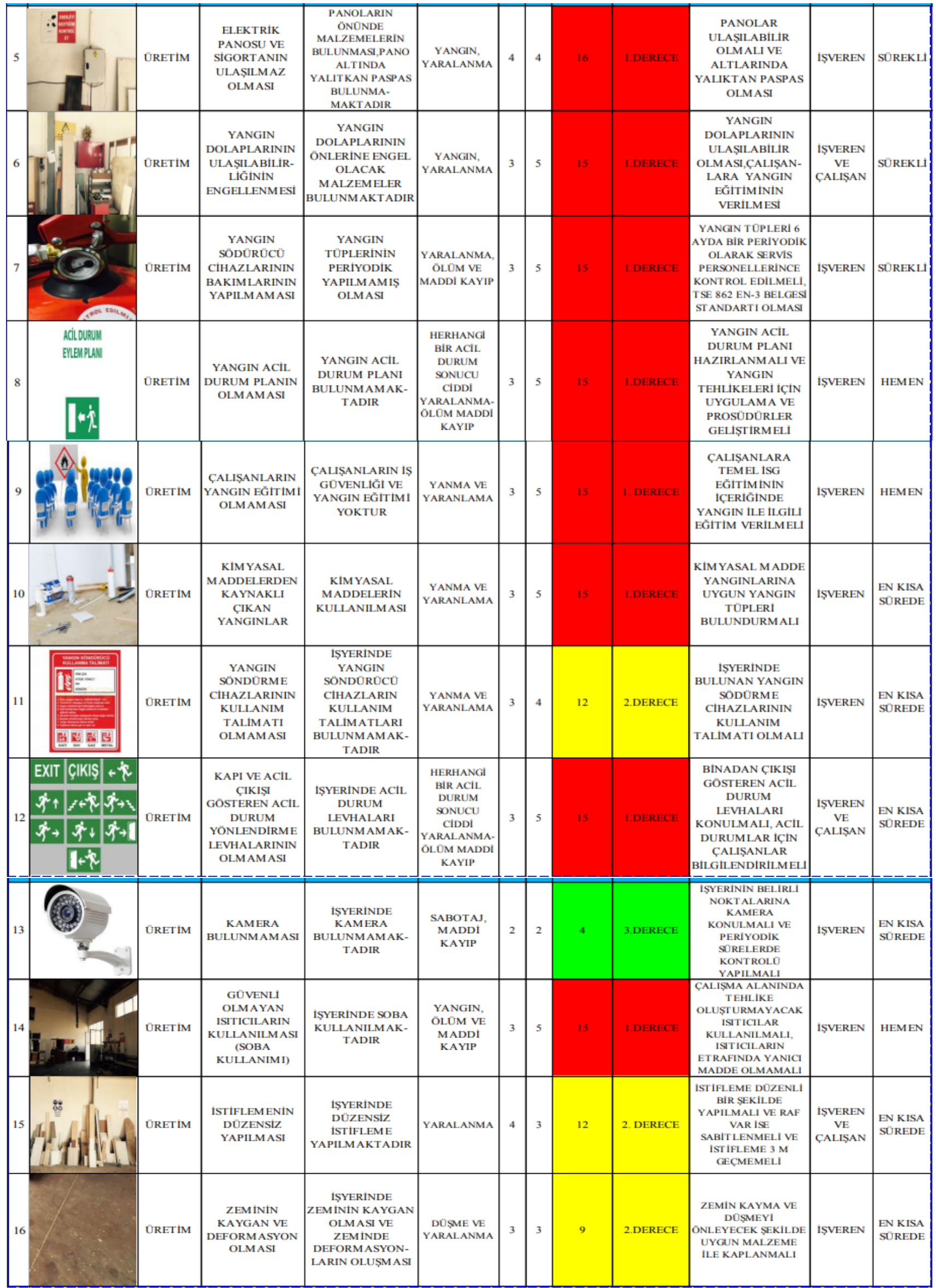


Tablo 5 (Devam). Risk Analiz Tablosu

\begin{tabular}{|c|c|c|c|c|c|c|c|c|c|c|c|c|}
\hline 17 & $\begin{array}{l}\text { SigARA } \\
\text { içiLMEZI }\end{array}$ & ÜRETIM & \begin{tabular}{|c|} 
ISYYERINDE \\
ŞGARA VE \\
TÜTÜN \\
ÜRUNLERININ \\
KULLANILMASI
\end{tabular} & $\begin{array}{c}\text { ÜRETIM YERINDE } \\
\text { SIGARA VE TÚTÚN } \\
\text { URUUNLERININ } \\
\text { KULLANILMAK- } \\
\text { TADIR }\end{array}$ & $\begin{array}{l}\text { ZEHIRLENME } \\
\text { VE YANGIN }\end{array}$ & 1 & 5 & 5 & 3.DERECE & $\begin{array}{l}\text { ISLLENME ICCERISINDE } \\
\text { SIGARA VE TOTONON } \\
\text { ORONLERI ICCILMESI } \\
\text { YASAKL.ANMALI, } \\
\text { IKAZ VE UYARI } \\
\text { LEVHALARI } \\
\text { ASLLMALII }\end{array}$ & $\begin{array}{l}\text { ISSVEREN } \\
\text { VE } \\
\text { ÇALIŞAN }\end{array}$ & SÜREKLI \\
\hline 18 & & ÜRETIM & \begin{tabular}{|c|} 
ÇALIŞMA \\
ALAANINDA \\
MALZEMELERIN \\
DAĞINIK \\
SEKILDE \\
BULUNMASI
\end{tabular} & \begin{tabular}{|c|} 
ÇALIȘMA \\
ALANINDA \\
MALZEMELERIN \\
DAĞINIK ȘEKILDE \\
BULUNMAKTADIR
\end{tabular} & $\begin{array}{c}\text { DU\$ME VE } \\
\text { YARAL_ANMA }\end{array}$ & 4 & 3 & 12 & 2.DERECE & \begin{tabular}{|c} 
KULLANILMAYAN \\
MALZEMEL.ERIN \\
ISTIFI IÇIN DEPO \\
ALANI \\
OLUȘTURULMALI \\
VE DEPO ALANI \\
DÜZENLI OLMALI
\end{tabular} & ÇALIȘAN & SÛREKLI \\
\hline 19 & & URETIM & $\begin{array}{c}\text { ÇALIȘMA } \\
\text { ALANININ } \\
\text { YETERSIZ } \\
\text { OLMASI }\end{array}$ & $\begin{array}{l}\text { ISSYERINDE } \\
\text { ÇALISSMA } \\
\text { ALANININ } \\
\text { YETERLI } \\
\text { OLMAYIȘI }\end{array}$ & $\begin{array}{c}\text { DUSME VE } \\
\text { YARALANMA }\end{array}$ & 3 & 4 & 12 & 2.DERECE & $\begin{array}{l}\text { ÇALIȘANIN IS } \\
\text { YAPTIĞI YERDE } \\
\text { RAHAT HAREKET } \\
\text { EDEBILECEK BIR } \\
\text { SERBEST ALAN } \\
\text { OLUSTTURULMALI }\end{array}$ & ÇALIȘAN & SÜREKLI \\
\hline 20 & & ÜRETIM & \begin{tabular}{|} 
MERDIVENLERIN \\
UYGUNSUZ \\
OLMASI
\end{tabular} & $\begin{array}{l}\text { ISYERINDE } \\
\text { BULUNAN } \\
\text { MERDIVENLERIN } \\
\text { UYGUNSUZ } \\
\text { OLMASI }\end{array}$ & $\begin{array}{c}\text { DO\$ME VE } \\
\text { YARAL_ANMA }\end{array}$ & 4 & 3 & 12 & 2.DERECE & $\begin{array}{c}\text { MERDIVENLER } \\
\text { YETERLI } \\
\text { GENIȘLIKTE } \\
\text { OLMALIVE } \\
\text { MERDIVEN } \\
\text { BOYUNCA } \\
\text { TIRABZANLAR } \\
\text { MEVCUT OLMALI }\end{array}$ & ISSVEREN & $\begin{array}{l}\text { EN KISA } \\
\text { SŪREDE }\end{array}$ \\
\hline 21 & & ÜRETIM & $\begin{array}{l}\text { DOLAPLARIN } \\
\text { SABITLENMIŞ } \\
\text { OLMAMASI }\end{array}$ & $\begin{array}{l}\text { IȘYERINDE } \\
\text { BULUNAN } \\
\text { DOLAPLARIN } \\
\text { SABITLENMESI } \\
\text { YAPILMAMIS }\end{array}$ & YARALANMA & 3 & 3 & 9 & 2.DERECE & $\begin{array}{l}\text { DOLAPLARIN ACIL } \\
\text { BIR DURUMDA } \\
\text { DEVRILMEMESI } \\
\text { IÇIN SABITLENMELL }\end{array}$ & ISSVEREN & $\begin{array}{l}\text { EN KISA } \\
\text { SUUREDE }\end{array}$ \\
\hline 22 & & ÜRETIM & \begin{tabular}{|} 
ELEKTRIKLI \\
CIHAZLARIN \\
TOPRAKLANMIS \\
OLMAMASI
\end{tabular} & \begin{tabular}{|c|} 
ISSYERINDEKI \\
ELEKTRIK ILE \\
ÇALIȘAN \\
MAKINALARIN \\
TOPRAKLANMASI \\
YAPILMAMIŞ
\end{tabular} & $\begin{array}{c}\text { YARAL.ANMA } \\
\text { VE MAKINE } \\
\text { HASARI }\end{array}$ & 3 & 5 & 15 & 1.DERECE & \begin{tabular}{|c} 
ELEKTRIKLI \\
CIHAZLAR UYGUN \\
SEKILDE \\
TOPRAKLANMASI,YI \\
LDA BIR DEFA \\
DIRENÇ ÓLÇLLMELI \\
VE \\
BELGELENDIRILMELI
\end{tabular} & IŞVEREN & $\begin{array}{l}\text { EN KISA } \\
\text { SÛREDE }\end{array}$ \\
\hline 23 & & URETIM & \begin{tabular}{|c|} 
KESILEN \\
MALZEMELERIN \\
MAKINA \\
CCEVRESINDE \\
BIRAKILMASI
\end{tabular} & \begin{tabular}{|c|} 
KESILMIS \\
MALZEMENIN \\
MAKINALARIN \\
ÇEVRESINDE \\
BULUNMAKTADIR
\end{tabular} & $\begin{array}{c}\text { DÓ\$ME VE } \\
\text { YARAL_ANMA }\end{array}$ & 4 & 3 & 12 & 2.DERECE & \begin{tabular}{|c|} 
MAKINEDE ISLENEN \\
MALZEMELER \\
MAKINANIN \\
YANINDA \\
BULUNDURMAMALI, \\
KULLANIM SONRASI \\
TEMIZLIGi \\
YAPILMALI \\
\end{tabular} & ÇALIȘAN & SÛ́REKLI \\
\hline 25 & & ÜRETIM & \begin{tabular}{|c|} 
TALASSLARIN \\
TEMIZLENMEM E- \\
SI \\
\\
\\
TEZGAH \\
ÜZERINDE \\
MALZEMELERIN \\
DAĞINIK \\
BULUNMASI
\end{tabular} & $\mid$\begin{tabular}{|l} 
TALASSLAR YERDE \\
VE MAKINALARIN \\
ETRAFINDA \\
BULUNMAKTADIR \\
\\
ÇALIŞILAN \\
TEZGAH \\
UZERINDE \\
MALZEMELERIN \\
DAĞINIK \\
BULUNMASI
\end{tabular} & $\begin{array}{l}\text { YARAL.ANMA } \\
\text { VE MESLEK } \\
\text { HAST ALIGI }\end{array}$ & 3 & 3 & 12 & 2.DERECE & \begin{tabular}{|} 
TALAȘLARIN \\
TEMIZLENMESI \\
ICCIN BIR FIRÇA \\
KULLANILMALI, \\
BASINÇLI HAVA \\
VEYA ELLE \\
YAPILMAMALI \\
\\
KULLANILMAYAN \\
MALZEMELER VE \\
CALIȘLAN ALETLER \\
TEZGAH OZERINDE \\
BULUNDURULMAMAS \\
I VE CCALIŞANLARIN \\
BILGILENDIRILMESI
\end{tabular} & $\begin{array}{c}\text { ÇALIȘAN } \\
\\
\\
\text { IŞVEREN } \\
\text { VE } \\
\text { ÇALIȘAN }\end{array}$ & $\begin{array}{l}\text { SÜREKLI } \\
\text { SÜREKLL }\end{array}$ \\
\hline 26 & 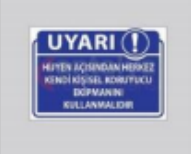 & ÜRETIM & $\begin{array}{c}\text { HIJYEN } \\
\text { KOŞULLARINA } \\
\text { UYULMAMASI }\end{array}$ & \begin{tabular}{|c|} 
ÇALISSILAN \\
ORTAMDA HIJYEN \\
KURALLARINA \\
UYULMAMAKTA- \\
DIR
\end{tabular} & $\begin{array}{c}\text { MESLEEK } \\
\text { HASTALIĞ }\end{array}$ & 2 & 4 & 8 & 2.DERECE & \begin{tabular}{|l} 
TOM CCALISANLARA \\
GENEL. HIJYEN \\
BILGISI VERILMELI \\
VE GEREKLII \\
ONNLEMLER \\
ALINMALI
\end{tabular} & ÇALIȘAN & $\begin{array}{l}\text { GEREKL. } \\
\text { KOŞUL- } \\
\text { LAR } \\
\text { OLUSSTU- } \\
\text { ǴUNDA }\end{array}$ \\
\hline 27 & & URETIM & $\begin{array}{l}\text { HAVALANDIR- } \\
\text { MANIN } \\
\text { YETERSIZ } \\
\text { OLMASI }\end{array}$ & $\begin{array}{l}\text { ÇALIȘILAN } \\
\text { ORTAMDA } \\
\text { HAVANADIRMA } \\
\text { YETERSIZDIR }\end{array}$ & $\begin{array}{c}\text { MESLEK } \\
\text { HAST ALIGII }\end{array}$ & 4 & 2 & 8 & 2.DERECE & $\begin{array}{c}\text { HAVALANDIRMA } \\
\text { LOKAL YA DA DOGAL } \\
\text { OLARAK } \\
\text { YAPTIRILMALI }\end{array}$ & $\begin{array}{l}\text { ISSVEREN } \\
\text { VE } \\
\text { ÇALIŞAN }\end{array}$ & SÜREKLI \\
\hline 28 & & URETIM & \begin{tabular}{|} 
SOYUNMA YERI \\
VE \\
DOLAPLARININ \\
BULUNMAMASI
\end{tabular} & $\begin{array}{c}\text { ISSYERINDE } \\
\text { CCALISANLARIN } \\
\text { KIYAFETLERINI } \\
\text { DEĞIȘTIREBILECE } \\
\text { K SOYUNMA YERI } \\
\text { VE DOLAPLARI } \\
\text { BULUNM AMAK- } \\
\text { TADIR }\end{array}$ & $\begin{array}{l}\text { TAKILMA, } \\
\text { DOSSME }\end{array}$ & 2 & 4 & 8 & 2.DERECE & $\begin{array}{c}\text { SOYUNMA ODASI } \\
\text { YAPILMALI VE HER } \\
\text { ÇALISAAN IÇIN AYRI } \\
\text { DOLAP VERILMELI, } \\
\text { ELBISE DOLAPLARI } \\
\text { YANYANA IKI } \\
\text { BÖLMELI OLMALI VE } \\
\text { YA IKI DOLAP } \\
\text { VERILMELI }\end{array}$ & $\begin{array}{l}\text { IŞVEREN } \\
\text { VE } \\
\text { ÇALIŞAN }\end{array}$ & $\begin{array}{l}\text { EN KISA } \\
\text { SÜREDE }\end{array}$ \\
\hline
\end{tabular}


Tablo 5 (Devam). Risk Analiz Tablosu

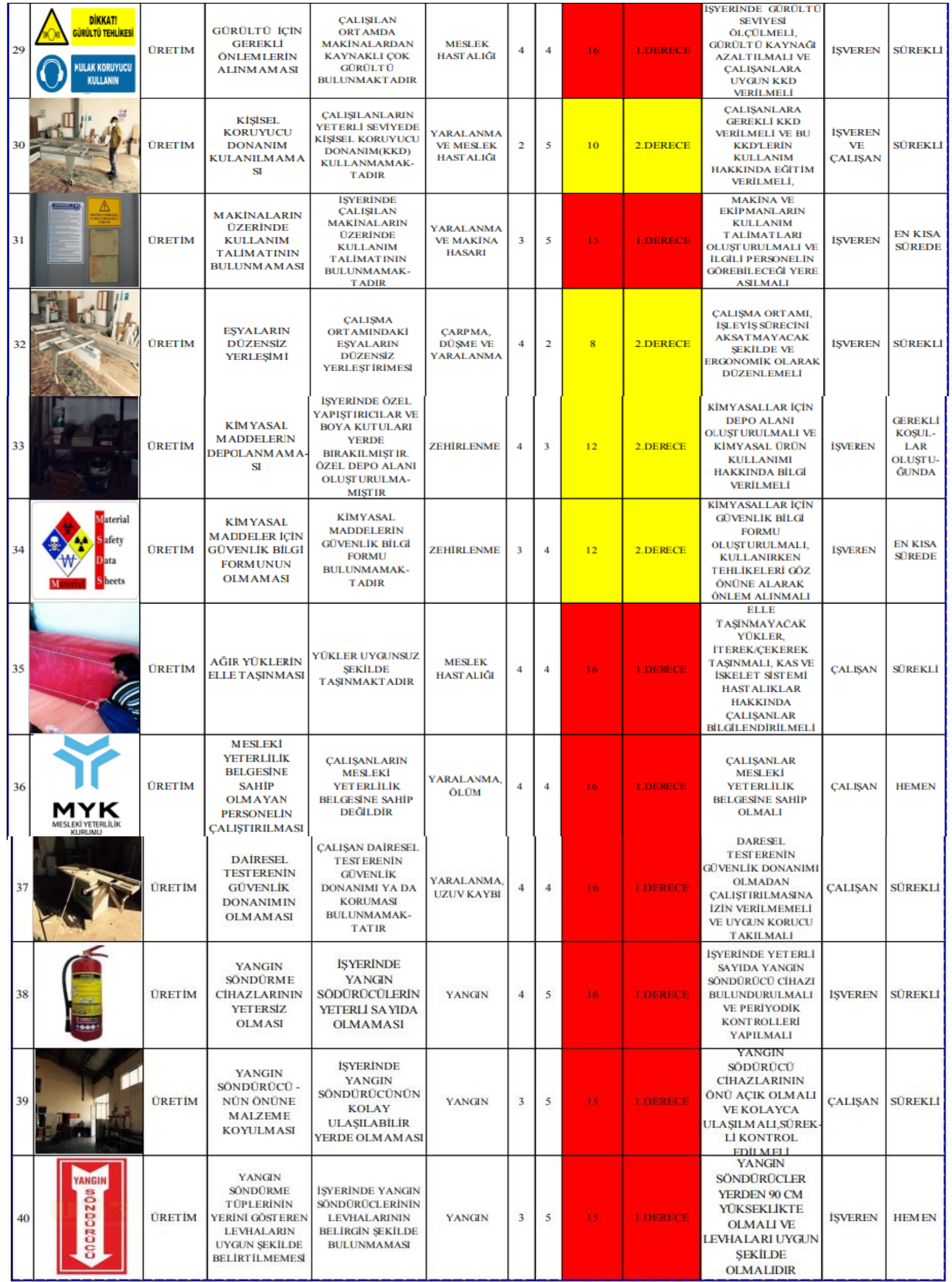


Tablo 5 (Devam). Risk Analiz Tablosu

\begin{tabular}{|c|c|c|c|c|c|c|c|c|c|c|c|c|}
\hline 41 & & ÜRETIM & $\begin{array}{c}\text { YANGIN } \\
\text { ALGILAMA } \\
\text { SISTEMININ } \\
\text { OLMAMASI }\end{array}$ & $\begin{array}{l}\text { ISSYERINDE } \\
\text { YANGIN } \\
\text { ALGILAMA } \\
\text { SISTEMININ } \\
\text { OLMAMASI }\end{array}$ & YANGIN & 3 & 5 & 15 & 1.DERECE & $\begin{array}{l}\text { YANGIN ALGILAMA } \\
\text { SISTEMININ TEMIN } \\
\text { EDILMESI VE } \\
\text { PERIYODIK } \\
\text { KONTROLLERINI } \\
\text { YAPILMALI }\end{array}$ & ISSVEREN & $\begin{array}{l}\text { EN KISA } \\
\text { SÜREDE }\end{array}$ \\
\hline 42 & & $\begin{array}{l}\text { ISSLETME } \\
\text { GENELLI }\end{array}$ & $\begin{array}{l}\text { YANGIN ALARM } \\
\text { BUTONU VE } \\
\text { SIRENI } \\
\text { BULUNMAMASI }\end{array}$ & $\begin{array}{c}\text { ISYYERINDE } \\
\text { YANGIN ALARM } \\
\text { BUTONU VE } \\
\text { SIRENI } \\
\text { BULUNMAM ASI }\end{array}$ & YANGIN & 3 & 5 & 15 & 1.DERECE & \begin{tabular}{|c|} 
ISTYERINDE YANGIN \\
ALARM \\
BUTONLARI \\
YETERLI SAYIDA \\
OLMALI VE \\
PERSONEL \\
BILGILENDIRILMELI. \\
DIR \\
\end{tabular} & ISSVEREN & $\begin{array}{l}\text { EN KISA } \\
\text { SÜREDE }\end{array}$ \\
\hline 43 & $\underset{\substack{\text { DiKKAT } \\
\text { ELEKTRIK KABLOSU }}}$\[ \Delta \]$$ & \text {$ÜRETIM }$ & $\begin{array}{c}\text { ELEKTRIK } \\
\text { TESISATIYLA } \\
\text { ILGILI UYARI } \\
\text { LEVHASI } \\
\text { BULUNMAMASI }\end{array}$ & $\begin{array}{l}\text { ISSYERINDE } \\
\text { ELEKTRIK } \\
\text { TESISATI ILE } \\
\text { ILGILI UYARI } \\
\text { LEVHALARININ } \\
\text { BULUNMAMASI }\end{array}$ & $\begin{array}{c}\text { YARALANMA } \\
\text { OLLOM }\end{array}$ & 2 & 4 & 8 & \text {$2.DERECE }$ & $\begin{array}{|c|}\text { IŞYERINDE } \\
\text { ELEKTRIK } \\
\text { TESISTININ } \\
\text { BULUNDUĞU } \\
\text { YERLERE GEREKLI } \\
\text { UYARI LEVHALARI } \\
\text { ASILMALI }\end{array}$ & \text {$ISSVEREN }$ & \text {$SÜREKLI }$ \\
\hline 44 & & \text {$ÜRETIM }$ & $\begin{array}{c}\text { TOZLU } \\
\text { ORTAMDA } \\
\text { ÇALISৃILMASI }\end{array}$ & $\begin{array}{l}\text { ÇALIȘMA } \\
\text { ORTAMININ } \\
\text { TOZLU OLMASI }\end{array}$ & $\begin{array}{l}\text { MESLEEK } \\
\text { HAST ALIGI }\end{array}$ & 3 & 4 & 12 & \text {$2.DERECE }$ & $\begin{array}{c}\text { ISYERINDE TOZ } \\
\text { TUTMA SISTEMI } \\
\text { BULUNDURULMALI } \\
\text { VE TOZ MASKELERI } \\
\text { KULLANDIRILM ALI }\end{array}$ & $\begin{array}{l}\text { IŞVEREN } \\
\text { VE } \\
\text { ÇALIŞAN }\end{array}$ & $\begin{array}{l}\text { EN KISA } \\
\text { SÜREDE }\end{array}$ \\
\hline 45 & \text {$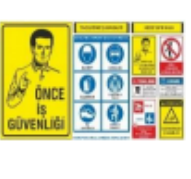 }$ & \text {$URETIM }$ & $\begin{array}{c}\text { UYARI VE IKAZ } \\
\text { LEVHALARININ } \\
\text { DOĞRU YERDE } \\
\text { KULLANILMAM } \\
\text { A-SI }\end{array}$ & $\begin{array}{c}\text { CALISMMA } \\
\text { ORTAMINDA } \\
\text { UYARI VE IKAZ } \\
\text { LEVHALARININ } \\
\text { DOĞRU } \\
\text { NOKTALARDA } \\
\text { OLMAMASI }\end{array}$ & $\begin{array}{c}\text { IS KAZASI, } \\
\text { YARAL_ANMA }\end{array}$ & 4 & 4 & 15 & \text {$1.DERECE }$ & $\begin{array}{|c|}\text { ISSYERINDE UYARI } \\
\text { VE IKAZ } \\
\text { LEVHALARININ } \\
\text { KAYNAĞA YAKIN } \\
\text { OLMALI VE } \\
\text { ÇALISSANLAR } \\
\text { BILGILENDIRILMELI }\end{array}$ & \text {$ISSVEREN }$ & \text {$SÜREKLI }$ \\
\hline 46 & $\begin{array}{l}\text { Eskimis, Yipranmıs } \\
\text { Kisisel Koruyuculan } \\
\text { Kullanma, Amirine } \\
\text { Bildir }\end{array}$ & \text {$ÜRETIM }$ & $\begin{array}{l}\text { YIPRANMIS KKD } \\
\text { LERIN } \\
\text { KULLANILMASI }\end{array}$ & $\begin{array}{c}\text { IŞYERINDE } \\
\text { YIPRANMIŞ KKD } \\
\text { LERIN } \\
\text { KULLANILMASI }\end{array}$ & \text {$YARALANMA }$ & 2 & 5 & 10 & \text {$2.DERECE }$ & $\begin{array}{|c|}\text { ÇALISSANLARA } \\
\text { EĞITIM VERILMELI, } \\
\text { KKD BELIRLI } \\
\text { SÜRELERDE } \\
\text { KONTROLLŬ } \\
\text { ȘEKILDE } \\
\text { DEĞIȘTIRILMELI }\end{array}$ & \text {$ÇALIȘAN }$ & \text {$HEMEN }$ \\
\hline 47 & & \text {$ÜRETIM }$ & $\begin{array}{c}\text { ÇALIȘMA } \\
\text { ORTAMININ } \\
\text { SICAKLIK } \\
\text { DEĞERLERININ } \\
\text { YÜKSEK OLMASI }\end{array}$ & $\begin{array}{l}\text { IŞYERINDE } \\
\text { ÇALIȘMA } \\
\text { ALANININ } \\
\text { SICAKLIK } \\
\text { DEĞERLERININ } \\
\text { YÜKSEK OLMASI }\end{array}$ & $\begin{array}{c}\text { CALISANLAR- } \\
\text { DA RAHAT SIZ- } \\
\text { LIK }\end{array}$ & 2 & 1 & 2 & \text {$3.DERECE }$ & $\begin{array}{|c|}\text { ÇALISSMA } \\
\text { ORTAMININ } \\
\text { SICAKLIK VE NEM } \\
\text { OLCCÜMLERI } \\
\text { YAPILMALI VE } \\
\text { GEREKLI } \\
\text { ONLEMLER } \\
\text { ALINMAII } \\
\end{array}$ & \text {$IŞVEREN }$ & $\begin{array}{l}\text { GEREKLI } \\
\text { KOŞUL- } \\
\text { LAR } \\
\text { OLUŞTU } \\
\text { RUKDU- } \\
\text { GUUNDA }\end{array}$ \\
\hline 48 & \text {$e }$ & $\begin{array}{l}\text { ISSLETME } \\
\text { GENELI }\end{array}$ & $\begin{array}{|}\text { ÇALIŞANLARA } \\
\text { IŞE GIRIŞTE } \\
\text { OLASI } \\
\text { TEHLIKELERE } \\
\text { KARŞI EĞITIMIN IN } \\
\text { VERILMEMESI }\end{array}$ & $\begin{array}{l}\text { ISSYERINDEKI } \\
\text { ÇALIŞANLARA IŞE } \\
\text { GIRIŞTE } \\
\text { TEHLIKELERE } \\
\text { KARŞI EĞITIMIN } \\
\text { VERILMEMESI }\end{array}$ & $\begin{array}{c}\text { IS KAZASI, } \\
\text { YARAL.ANMA }\end{array}$ & 4 & 5 & 20 & \text {$1.DERECE }$ & $\begin{array}{c}\text { IŞYERINDE } \\
\text { ÇALIȘANLARIN IŞE } \\
\text { BAȘLAMADAN } \\
\text { ONCE ISG EĞITIMI } \\
\text { VERILMELI }\end{array}$ & \text {$IȘVEREN }$ & \text {$HEMEN }$ \\
\hline 49 & & $\begin{array}{l}\text { ISSLETME } \\
\text { GENELI }\end{array}$ & $\begin{array}{c}\text { SERTIFIKALI ILK } \\
\text { YARDIM } \\
\text { PERSONELI } \\
\text { BULUNMAMASI }\end{array}$ & $\begin{array}{l}\text { IŞYERINDE ILK } \\
\text { YARDIM EĞITIMI I } \\
\text { ALMIŞ } \\
\text { PERSONELIN } \\
\text { BULUNMAMASI }\end{array}$ & \text {$YARALANMA }$ & 3 & 4 & 12 & \text {$2.DERECE }$ & $\begin{array}{c}\text { IȘYERINDE } \\
\text { ÇALIȘANLARA ILK } \\
\text { YARDIM EĞITIMIMI } \\
\text { VERILMELİ }\end{array}$ & \text {$ISSVEREN }$ & $\begin{array}{l}\text { EN KISA } \\
\text { SÛREDE }\end{array}$ \\
\hline
\end{tabular}

Yapılan risk analiz çalışmasında 26's1 "Yüksek Risk”, 20'si “Orta Risk”, 3“ü “Düşük Risk" olarak toplam 49 risk tespit edilmiştir.

\section{Konu hakkındaki çalışmalar} incelendiğinde Güneysu (2016) tarafından gerçekleştirilen çalışmada bir kereste işletmesinin kereste ve panel bölümlerinde L Tipi Matris Metodu kullanarak risk analiz çalışması gerçekleştirilmiş ve 6 adet önemli risk, 21 adet orta düzeyde risk ve 6 adet katlanılabilir risk belirlenmiştir. ${ }^{17}$
Oral ve Gülsün'ün (2019) çalışmasında örnek bir mobilya atölyesinde çalışma ortam koşulları, makine insan ve çevre faktörleri bir arada değerlendirilerek elde edilen veriler doğrultusunda Fine Kinney risk değerlendirme yöntemi kullanılarak risk analiz çalışması gerçekleştirilmiş ve 71 adet çok yüksek risk, 2 adet yüksek risk ve 2 adet önemli risk tespit edilmiştir. ${ }^{18}$

Yılmaz (2015) mobilya firmalarının iş sağllğ 1 ve güvenliği ile ilgili mevcut durumlarının belirlenmesine yönelik 
gerçekleştirdiği çalışmasında, çalışma kapsamında yer alan mobilya firmaları, genel hareket eden araçlar, hareketli makineler, elektrik tesisatı, yangın, patlayıcı madde, kimyasal madde ve aydinlatma konuları ele alınarak Fine Kinney yöntemi ile risk analizi gerçekleştirilmiştir. Çalışma sonucunda mobilya atölyesinde 50 düşük risk, 34 önemsiz risk, 20 tolerans gösterilemez risk, 13 önemli risk, 5 esaslı risk tespit dilerek çözüm önerilerinde bulunulmuştur. ${ }^{19}$

\section{SONUÇ VE ÖNERÍLER}

Bu çalışmada ahşap ve mobilya imalatı yapan bir işletme iş sağ lığı ve iş güvenliği açısından değerlendirmeye alınmıştır. Bu uygulamada, yaygın olarak tercih edilen ve kullanımı hızlı ve basit olan L Tipi Matris yöntemi kullanılmıştır. L Tipi Matris Metodu seçilerek hazırlanan bu risk değerlendirme çalışmasının sonucunda, uygulamanın yapıldığı işletmede 26's1 "Yüksek Risk", 20'si "Orta Risk", 3“ü "Düşük Risk" olarak toplam 49 risk tespit edilerek, her bir risk için ayrı olarak "Düzeltici/Önleyici Faaliyet" belirlenmiştir.

$\mathrm{Bu}$ işyerindeki belirlenen riskleri kabul edilebilir seviyeye indirebilmek için gerekli öneriler aşağıda belirtilmiştir:

- İşletmede çalışanlara iş sağlığı ve güvenliği konularında eğitimler verilmelidir.

- Çalışma ortamının hijyeni sağlanmalı ve çalışanlara hijyen konusunda eğitim verilmelidir.

- Çalışanların sağlık kontrolleri düzenli olarak yapılmalı, hijyen konusunda gerekli önlemler alınmalıdır.

- Çalışanların önerileri ve şikâyetleri dikkate alınarak değerlendirilmelidir.

- İş kazaları ve meslek hastalıkları konusunda işveren bilgilendirilmeli ve çalışanlara eğitim verilmelidir.

- İşletmenin üretim alanında çalışanın maruz kaldığ gürültü ve toz, çalışma ortamındaki aydınlatma, havalandırma ve sıcaklık etkenlerinin ölçümleri yapılmalı ve gerekli tedbirler alınmalidır.

- Çalışanların daha dikkatli olmalarını sağlayacak uyarı levhaları ve işaret levhaları yeterli sayıda bulunmalıdır. İşyeri makina ve ekipmanların kullanım talimatları görülebilir ve anlaşılabilir bir şekilde olmalı ve uygun koruyucu takılmalıdir.

- Çalışanlara uygun kişisel koruyucu donanımları verilmeli ve kullanılması zorunlu hale getirilmelidir. Bu kişisel koruyucu donanımlar yıprandığında, işlev göremez hale gelmeden değiştirilmelidir.

- Çalışma alanında kullanılan kimyasalların güvenlik bilgi formları oluşturulmalıdır.

- Güvenli Acil durum planı oluşturulmalı ve herhangi bir acil durum için çalışanlar bilgilendirilmelidir.

- Yangın dolapları ulaşılabilir olmalı, yangın söndürme cihazları yeterli sayıda ve kullanım talimatları anlaşılabilir olmalı ve cihazların bakımı periyodik olarak yapılmalıdır.

- İşletmede bulunan prizler kapakla korunaklı olmalı, elektrik bağlantı kabloları ve açık uçlar yalıtkan kapak ile kapatılmalı, elektrik kabloları dağınık şekilde olmamalı ve kisa kablolar kullanılmalıdır.

- Yangın acil durum planı hazırlanmalı ve çalışanlara yangın eğitimi verilmeli, yangın tehlikeleri için uygulama ve prosedürler geliştirilmelidir.

- Depo kısmında istifleme düzenli bir şekilde yapılmalı ve 3 metreyi geçmemelidir, kimyasal malzemelerin saklanma alanında raf kullanılmalıdır.

- Makinede işlenen malzemeler makine etrafinda bulundurulmamalı, kullanım sonrası temizliği yapılmalıdır.

- Üretimde meydana gelen talaş ve atıkların temizlenmesinde fırça kullanılmalı, basınçlı hava veya elle yapılmamalidir. 
- İşletmede bulunan dolaplar sabitlenmeli ve soyunma odasi yapılmalı ve dolaplar her çalışan için yan yana iki bölmeli olmalı veya iki dolap verilmelidir.
- İşletme içerisindeki merdivenler yeterli genişlikte olmalı ve merdiven boyunca tırabzanlar mevcut olmalidir.

\section{KAYNAKLAR}

1. Korkmaz, A. ve Avsallı, H., (2012). "Çalışma Hayatında Yeni Bir Dönem: 6331 Sayılı I̦s Sağlığı ve Güvenliği Yasası, Süleyman Demirel Üniversitesi Sosyal Bilimler Dergisi, Sayı 26, 153-156.

2. Eker, T. (2013). İs Sağlığı ve Güvenliği Kapsamında Risk Analizi ve Metal Sektöründe Bir Uygulama. Haliç Üniversitesi Fen Bilimleri Enstitüsü, Yüksek Lisans Tezi, İstanbul.

3. 2016 Yılı İş Kazası ve Meslek Hastalıkları İstatistikleri, Tusiag, https://tuisag.com/2016-yili-is-kazasi-meslekhastaliklari istatistikleri/ (Erişim Tarihi, 15.01.2020).Kurtuluş, K. (1998). Pazarlama Araştırmaları. 6. Bask1. İstanbul Üniversitesi. İstanbul.

4. Çelenk Kaya, E. Başkan, Takaoğlu Z. Ölmezoğlu İri, N.İ. Aydemir, G. (2018). "Meslek ve Teknik Eğitim Kurumu İçin Örnek Risk Analiz Çalışması”. 1. Uluslararası Afet Yönetimi Kongresi Bildiriler Kitabı İçinde (501-513). Gümüşhane: Gümüsshane Üniversitesi.

5. URL-1. İş Sağlığı e güvenliğinin tanımı http://etemkose.cbu.edu.tr/wpcontent/uploads/2017/02/ISG_ Der _Notlari_Etem_KOSE_01.02.2020-Vize.pdf (Erişim Tarihi. 15.01.2020)

6. Bașkan, Takaoğlu Z. Çelenk Kaya, E. Ölmezoğlu İri, N.İ. (2018). İş Güvenliği Uzmanlarının Yaşadığı Sorunlar. Gümüşhane Üniversitesi Sağlık Bilimleri Dergisi 7(2),1-9.

7. Molak, V. (1997). Fundamentals of Risk Analysis and Risk Management, Boca Raton:CRC Press Lewis Publishers.

8. Modarres, M. (1993). "Increasing Performance of Engineering Systems". Reliability Review, J., vol. 6, No. 182, 21-24.

9. İş Sağlığı ve Güvenliği Risk Değerlendirmesi Yönetmeliği. (2012). Yayımlandığı Resmi Gazete Tarihi: 29/12/2012, Say1 28512.

10. Çelenk Kaya, E. Ölmezoğlu İri, N.İ. Başkan, Takaoğlu Z. (2018). "Risk Değerlendirmesi Ne Kadar Önemli? İşveren Bakış Açısı" Gümüşhane Üniversitesi Sağlık Bilimleri Dergisi, 7(4), 10-18.

11. Gülsoy, K. Ü. (2015). Mobilya Boyahanelerinde Risklerin Tespiti ve Çalışanların Kimyasal Maruziyetinin Değerlendirmesi”. Çalışma ve Sosyal Güvenlik Bakanlığı İş Sağlığ1 ve Güvenliği Genel Müdürlüğü, İş Sağlığı ve Güvenliği Uzmanlık Tezi, , Ankara.

12. Turan, G. (2013). Mobilya Üretimi Sürecinde Karşılașılan Başlıca Önemli Çevresel Etkilerin Çalışan Sağlığı Açısından Değerlendirilmesi, Namık Kemal Üniversitesi Fen Bilimleri Enstitüsü, Yüksek Lisans Tezi, Tekirdağ.

13. Özdağ, M. E., Çabuk, Y., Yeşilkaya, M. (2017). "Türkiye-Almanya Mobilya Dış Ticaretinin Yapay Sinir Ağları ile Tahmini”. Bartın Orman Fakültesi Dergisi, 19(2), 136-143.

14. URL-2 2016 Yılı İs Kazası ve Meslek Hastalıkları İstatistikleri, Tusiag, https://tuisag.com/2016-yili-iskazasi-meslek-hastaliklari-istatistikleri/ (Erişim Tarihi, 26.12.2019).
15. Gürlevik, T. (2016). Mobilya Sektöründe Ağaç Tozu Maruziyetinin Önlenmesinde Endüstriyel Havalandırma Tasarımı, Çalışma ve Sosyal Güvenlik Bakanlığı İş Sağlığı ve Güvenliği Genel Müdürlüğü, İş Sağlığı ve Güvenliği Uzmanlık Tezi, Ankara.

16. Özkılıç, Ö. (2014). Risk değerlendirmesi Atex direktifleri - Patlayıcı Ortamlar Büyük Endüstriyel Kazaların Önlenmesi ve Etkilerinin Azaltılması - Kantitatif Risk Değerlendirme. Türkiye İşveren Sendikaları Konfederasyonu TISK, Ankara.

17. Güneysu, G. (2016). Bir Kereste İşletmesi Üretim Sürecinde İş Sağlığı ve Güvenliği Risk Değerlendirme Çalışması, Bartın Üniversitesi Fen Bilimleri Enstitüsü, Yüksek Lisans Tezi, Bartın.

18. Oral, T., Gülsün, B. (2019). "Mobilya Atölyelerinde FıneKınney Yöntemi ile Risk Değerlendirmesi”. İş Sağlığg ve Güvenliği Akademi Dergisi, 1 (3),134-152.

19. Yılmaz, K. (2015). Ağaç İșleri Endüstrisinde İș Sağlığı ve Güvenliği ile İlgili Mevcut Durumun Belirlenmesi: Mobilya Sektörü Örneği. Hacettepe Üniversitesi Fen Bilimleri Enstitüsü, Yüksek Lisans Tezi, Ankara. 